This is a "Post-Print" accepted manuscript, which has been published in

Sport in Society: Cultures, Commerce, Media, Politics 2017, Vol. 20, No. 11, pp. 1684-1698

Please cite this publication as follows:

Hanna-Mari Ikonen and Samu Pehkonen 'I $<3$ my high-performance dog': love for the sport in agility coach representations in social media.

Sport in Society, ePrint version, Published online: 27 Mar 2017

You can download the free full version at:

http://www.tandfonline.com/eprint/wpAdcHHFJqw4Kwhfz965/full

or

http://dx.doi.org/10.1080/17430437.2017.1310201 


\title{
'I <3 my high-performance dog': Love for the sport in agility coach representations in social media
}

\author{
In contrast to its inception as intermission entertainment at the Crufts Dog \\ Show in the UK in the late 1970s, dog agility has become a worldwide \\ steadily professionalized and entrepreneurialized sport with reputable \\ coaches and training programs over the last decade. This change raises \\ concerns about the pressures placed on dogs. We look at the potential \\ incommensurability of 'loving' a dog as a companion animal and making \\ the dog engage in competitive sports. We evaluate texts, photographs and \\ videos from successful agility coaches and identify four types of loving \\ relationships through which the coaches express their commitment to the \\ sport. While an affinity for dogs appears important for building the \\ coaches' reputation and provides the justification for engaging the dog in \\ physically and mentally demanding sports, the question remains whether \\ this dogmanship can be straightforwardly turned into action.
}

\section{Introduction}

Most competitors love winning, but in the world of serious dog sport, it also takes love to win. In addition to presenting success in competitions, blog texts, photos and videos posted in social media by some of the world-class dog agility coaches and handlers testify to their love for their dogs. This article studies the intensive affective labour (e.g. Ahmed 2004; Hardt and Negri 2004) with which the coaches are intertwined through the potential incommensurability of love and success (Illouz 2007). As an emerging sport (Rinehart 2000), agility represents a social context where coaches' deepening engagement from serious leisure to acknowledged profession is continuously evaluated against internal norms by their potential customers in particular and society in general (e.g. Stebbins 1992; 2014; Baldwin and Norris 1999; Gillespie, Leffler and Lerner 2002). What we witness in commercial agility coaching, we argue, is the collective and the private or the economic and the emotional spheres becoming inextricably 
intertwined in a battle over love.

In contrast to its invention in the late 1970 s as an intermission entertainment at the Crufts Dog Show in the United Kingdom, over the last decade, agility has become a worldwide steadily professionalized and entrepreneurialized competitive sport. A handler directs her dog through an obstacle course in a race for both time and accuracy which requires advanced mental and physical capacities from both the handler and the dog. The community of agility practitioners entails a large number of people who consider agility as a proper sport despite its current official relation with national kennel clubs rather than sport federations and its public association with a playful leisure activity rather than emerging profession with systematic development of training methods and skills. Yet because of the close ties of dog agility to pet communities where compassion for and love of pets form an unquestionable norm — the process of the commodification and professionalization of agility does not fully follow the logics of blatant capitalism and professional sport (cf. Taylor and Garratt 2010) but rather, needs to do so affectively in 'dogs' terms', taking into account animal welfare.

While sports coaches in general have 'moral responsibilities reaching far beyond the purely technical and tactical' and extending 'to the nurturing and promotion of specific virtues that directly concern the attainment of the values of sport' (Hardman and Jones 2011,72 ), the non-human teammate makes agility coaching a distinct case also in terms of coaches' affective labour. Agility coaches need to build their entrepreneurship in accordance with certain assumptions about the role of the dog in the sport. Unlike in other competitive and established sports including non-human teammates, such as horse sport (Gilbert and Gillett 2012; Gillett and Gilbert 2014), many practitioners become engaged in agility with the primary intention of providing meaningful activity for their family pets; even those who acquire a dog having 
competitive goals in mind share their daily life with their non-human companions. As suggested by Gillett and Gilbert $(2014,4)$, contributions that bring together animal studies 'exploring the ways in which sport implicates human and non-human species' and sport studies 'broadening the view of sport and sporting environments to include animals' are much needed.

Having been participating in the agility sport for almost twenty years, we have witnessed the world of serious dog sport evolving as a collision of two different worlds: the world of companion animals, where unconditional love is an expectation (Beck and Katcher 1996, ix), and the world of competitive sport, where sacrifices are needed, compromises are avoided and dogs run the risk of becoming mere widgets in the race to achieve the highest performance (cf. Connor 2009). After reviewing literature on animal studies and sport studies and introducing our netnographic data and methods, we illustrate the clash of these two worlds by reference to general dog training philosophies. This is followed by a thematic analysis of four manifestations of love based on our reading of agility coaches' online self-presentations and advertising. Finally, we suggest that coaches develop an understanding of dogmanship to oscillate between these two apparently incompatible worlds in social media. Turning this loving attitude into reality, applying dogmanship could perhaps change both the world of pets and the world of success for the better, in the sense of how animals in general and dogs in particular are treated — both within and outside of the world of sport (also Lund 2014).

\section{Dogs as pets as high-performance athletes?}

In her introduction to critical pet studies, Nast (2006a; 2006b) maps the manifold human investment and interventions cast on dogs in current post-industrial societies. A shift has occurred 'from considering pets (especially dogs) as a species apart, to a 
reconsideration of pets (especially dogs) as profoundly appropriate objects of human affection and love' (Nast 2006a, 894). She links this love to the growth of postindustrial service and consumption sectors 'under largely neoliberal regimes of accumulation, pets figuring as both commodities themselves and as sites of intensely commodified investment tied to global inequalities' (Nast 2006a, 897). Department stores and luxury brands for pet clothes, salons for trimming the dogs, or celebrities with lapdogs wearing jewellery exemplify the quickly growing pet industries (Vänskä 2014).

The world of dog industries is not homogenous, however, and the identities constructed and lifestyles performed through consumption are very different (see Baldwin and Norris 1999). Handler-dog teams who compete in agility offer a good example of the general shift Nast describes, but at the same time, they pinpoint some exceptions that demand a more nuanced understanding of how neo-liberal societies and commercial sports work (e.g. Stokvis 2000). There are material artefacts, such as special footwear (for handlers), collars, leashes and coats (for dogs) and natural treats and designed toys to reward the dog in training; these are marketed primarily not to the large group of dog owners but to the subgroup of competitors. Agility dogs are taken to distinguished masseurs, physiotherapists and osteopaths, not for luxurious pampering but to keep their competitive edge. Training sessions and camps abroad, with top coaches (who have achieved their position by gaining success in competitions), are actively participated in. A new product, a toy for example, may rapidly become a 'musthave item' for those practitioners wanting to show their serious commitment among fellow competitors. Thus, an important part of making an agility dog comes about through commodities and communicating it online. 
Commodities and services offered by professional coaches go through a process of evaluation by the customers. The clients may feel themselves privileged to demand the best possible service, to justify the time and money spent on training as well as to expect tangible results in competitions. This systematic pursuit of acquiring special skills and knowledge locates agility practitioners - both the coaches and their clients as performers of serious leisure activities in Stebbins' $(1992,3 ; 2006)$ theoretical framework. Serious leisure builds around a core activity that is highly fulfilling and often results in practitioners finding a career in acquiring and expressing a combination of its special skills, knowledge, and experience in a way casual or project-based leisure activities do not (Stebbins 1992, 3).

However, as pointed out by Baldwin and Norris' $(1999,1)$ study of participants involved in American Kennel Club activities, agility practitioners blur the distinction between professionals/work and amateurs/leisure that motivates Stebbins' original work, because professional coaches with their dogs compete in same the events with amateurs. Further, many commercial coaches have drifted to their profession gradually and are thus not necessarily treated by fellow-practitioners as professionals. Based on an ethnography of dog sport, Gillespie, Leffler and Lerner $(2002,293)$ emphasise the contradictions that this may bring: On the one hand, dog sport is a highly moneyconsuming activity; on the other hand, it 'is considered shady to profit from dogs'. The commercial agility coaches need to work inside this double imperative. Finally, it is also difficult to separate agility-related core activities from on-going daily activities that living with a dog entails as dogs have to be taken care of also when the activity is put on hold (Baldwin and Norris 1999, 1).

For us, the most interesting aspect of seriousness comes through coaches being taken seriously in their efforts to develop new ways of communicating with dogs in 
competitive agility. This seriousness toward competitive goals has to be balanced with love for dogs. Whereas practitioners of serious leisure love what they do chiefly for the fulfilment it brings, love has also other roles in the moral code of dog sport and in the services delivered by coaching enterprises. Showing love becomes almost a compulsory asset for the coaches in their efforts to gain social competence and acceptance (Raisborough 1999).

While in general there is an ethical code to be followed in sport (including antidoping, respect for the opponent, etc.), animal-related sports are particularly valued with respect to the ways in which animals are treated. Social media adds an extra layer to the demand for the coaches to follow the moral code. The following quotation from equestrian sports illustrates the fact that one's behaviour towards the horse and one's emotional investment in the sport are continuously under surveillance:

[L]osing one's temper is not considered suitable according to the display rule of equestrianism. When the relationship is performed in blogs, the audience is expected to disapprove of negative emotions such as anger expressed by the owner, which leads to a need for repair. This appears in the form of explanations for the sudden outburst, assertion of love towards the horse, and explaining the horse's behaviour, thus giving oneself an excuse for deviating from the rule. (Schuurman 2104, 8)

An agility event can host hundreds of handlers and dogs. Therefore, any mistreatment of dogs will not go unnoticed. Because most agility coaches are also active competitors, the need to control one's emotions is vital in presenting their professional image, especially in social media. Showing their love for dogs is one way of doing it.

In the sociology of sport, love has appeared in multiple contexts, often as a face value which illustrates, for example, amateurs' fundamental love for sport (Eitzen 1989) or the commitment of sport volunteers (Cuskelly, Harrington, and Stebbins 2002), 
coaches (Schinke, Bloom, and Salmela 1995) or fans (Harvey and Piotrowska 2013; Caudwell 2015) to a particular sport or sport club as well as the relationship with technical equipment that makes sports available to those with physical disabilities (Apelmo 2012). On other love related topics, psychological research on passion has followed the path created by Vallerand (e.g. Vallerand et al. 2003), whose interest in motivation has led to an understanding of how individual differences in passion work (typically in the case of harmonious passion) or do not work (sometimes in the case of obsessive passion) in gaining success in sport (e.g., Vallerand et al. 2008). Instead of validating agility coaches' love and passion for the sport and for their dogs — a task we think would not give us a complete image of the emotionally complicated real and online world of agility — we are interested in how love becomes represented by the agility coaches as an integral and necessary part of their public appearance in social media, as it is the key channel by which the coaches can acquire their clientele.

\section{Researching social media}

To illustrate the importance of representing love in and through the professionalized and passion-driven agility coaching business, we analysed the blog texts, Facebook status updates, YouTube videos and web pages of professional agility coaches who are also successful agility competitors. The Internet is a place where the international agility community actively communicates. For research purposes it provides access to potential participants worldwide, thus allowing enough participants for researching a more specialized issue and easing data collection (Keller and Lee 2003, 211). Moreover, it offers a new type of research material such as the online self-representations of athletes as a mode of capitalist self-promotion (Lebel 2013; Pegoraro 2010).

The process of choosing the material was partly intuitive and based on our 
membership-bound knowledge of internationally recognized competitor-coaches, and it was partly systematic, based on going through successful agility world championship (AWC) participants from recent years and choosing worldwide examples from amongst them. As a result, twelve agility coaching enterprises were chosen, comprising approximately twenty coaches. ${ }^{1}$ Eight coaches are from Finland, which is the context we know best and which also has an impressive agility history in AWC. In addition, examples from Sweden, Denmark, Germany, the Czech Republic, the UK, the USA and Canada are included. In line with our effort to understand the social context for showing the love for dogs - the ways in which love is described, in which connections and to whom - we do not base our analysis on single examples or comparisons but use the insights from the coaches in aggregated form. The accounts are treated discursively and not as real-world statements. Because of our own involvement, our interpretations derive from a kind of participatory observation among social media communities we are a part of (Kozinets 2010).

In a recent contribution to research in online spaces, Morrow, Hawkins and Kern (2015) argue that the Internet is not simply an archive of data which is there for the

\footnotetext{
${ }^{1}$ Online content used in the article was collected between January 2014 and January 2016 from personal / business web pages (Wpp/Wpb), blogs (B) and personal / business Facebook pages (Fbp/Fbb): Agilityakatemia (Wpb) http://www.agilityakatemia.fi/; Gregg Derrett (Wpb) http://www.ultimateagility.com; Jenny Damm (B, Wpb, Fbp, Fbb) http://www.lotuseducation.se/en; Linda Meckenburg (Wpb) http://www.awesomepaws.us/; Lisa Frick (Wpp, Fbp) http://agilityborders.at/; Niinu Agility Sport \& Total Agility (Fbb, Fbp, Wpb) http://www.totalagility.fi/total-agility/; O/E Agility (Wpb) http://oreniusemanuelsson.se/; One Mind Dogs (several coaches) (Wpb, Fbb, Fbp) http://www.oneminddogs.com/; Sarah Lorentzen (B, Fbp) http://bordertreasure.blogspot.fi/; Silvia Trkman (Wpp, Fbp) http://www.lolabuland.com/; Susan Garrett (Wpb) http://susangarrettdogagility.com/
} 
taking. Instead, it is a political space which blurs the boundaries of private and public as it makes one's own ideas, feelings and perceptions public. The Internet has the potential to politicize everyday life, but it is still inevitably connected to capitalist consumption and production. Even if these issues are recognized, researchers' ways of handling Internet data have received less attention. Morrow, Hawkins and Kern (2015, 7-10) point out several ethical dilemmas in researching online environments, including questions about who is entitled to use these postings and for what purposes, and what are the researchers' ethics of lurking' on social media sites without needing to identify their observation.

While being aware of the ethical issues of coaches' online communication, we assume that there are many imagined audiences for whom professional agility coaches have to present themselves. These include not only their friends and clients who already admire them but also critics in the pet world, advocates of animal rights, non-dog-lovers and other people who may ultimately question their passion for dog sport. Coaches have to present themselves to audiences they cannot imagine; the activity has to hold water from anybody's perspective as well as the researchers'.

Based on our knowledge of coaches' dog histories as well as our experiences with our own and other amateurs' dogs, we know that not all stories are stories of success; living with high-performance dogs includes less glorious mundane matters which do not make headlines. There are differences between the coaches in how disappointments in big competitions are publicly handled, how failures in training are met with silence, how dead ends in the education process are (not) presented and how the breaching of ethical codes is (un)explained. Some events and their representations are specially tailored to be blogged (Morrow, Hawkins and Kern 2015, 7) in a manner which reflects certain trends, tastes, values and display rules (Schuurman 2014) of 
authors and blog readers and, accordingly, which excludes some others. Therefore, we also try to imagine what is not mentioned.

\section{Professional coaches versus pet caretakers: the possible clash of the two worlds}

By looking at the repetitive models of Facebook updates and YouTube videos posted by the coaches, it is possible to notice a preference for showing the harmonious type of passion toward the sport and the dogs. In social media, coaches celebrate their victories in competitions and equip their Facebook statuses with heart symbols $(<3)$, stickers and smileys highlighting the emotional relationship between them and their dogs. Other users typically comment posted photos with similar displays of love and affection. Although not downplaying the possibility of really liking and loving, it is important to note that by showing loving, commentators are simultaneously negotiating their connection with others online and finding the social groups to which they (want to) belong (Postmes, Spears and Lea 1998).

Postings underline the value of the dog's achievements; it may be emphasized that the dog has managed an imposing comeback to the top level after having overcome a serious injury. However, there are also signs of obsessive passion for the sport of agility: sometimes young dogs, first introduced as future stars, quietly disappear from the trials and updates, as they never reach the top level, resulting in, or often from, the handler's frustration. These type of associated negative emotions are not expressed publicly, as this expression would be non-preferred behaviour in social media.

The clash of two competing worlds is evident in the introduction of new dogs in to the sport. One of the changes compared to the early years of agility is that younger and younger dogs are making their way to the international top level. The rules in most countries set a minimum age for the dogs to enter the trials (around 18 months). When 
dogs under two years old qualify for the Agility World Championships, however, it is obvious that the training has started at very young age. A critical argument made by pet caretakers about enthusiastic hobbyists may arise: the puppy is selected as an object of the handler's desire to compete in dog sport, and as a result, puppies are trained too much and too hard, even if they are neither mentally nor physiologically ready for this training. The same criticism of putting too much pressure on too early in the career has been made concerning young human athletes (Salasuo, Piispa, and Huhta 2015), and the whole world of sport has been argued to be based on the exploitation of elite athletes (Connor 2009). Another criticism concerns the agility competitions that have been shown to cause stress for the dogs (Pastore et al. 2011).

The contrary argument, presenting the agility coaches' view of dog ownership, is that by engaging in agility, the handler offers her dog the possibility of expressing its basic instincts. Even if the puppy is selected with the forthcoming competition career in mind, the first thing for the handler is to build up a working relation with her puppy. The coaches prepare and sell DVDs and online courses to demonstrate the best ways to play with the forthcoming high-performance puppy. This same philosophy is reflected also in academic literature on teamwork and agility. Both Haraway $(2003 ; 2008)$ and Lund (2014) stress the aspects of reciprocal and voluntary communication and cooperation in agility. The 'team' itself, not the handler or the dog, has a unique position in the action.

Ultimately, the success of this early socialization and team-building is tested in competitions. Gaining success makes it possible to publicly show one's love for one's dog in front of the audience. Even if the team fails for some reason, the handler's love can be shown by following the moral code in which the dog should never be blamed for 
the faults. Thus, a high-performance dog is a happy dog living a happy doggy life (Lund 2014) and is not a stressed professional athlete. As one of the coaches puts it:

And please don't give me the examples of professional athletes! My dogs are NOT professional athletes. They're just three happy dogs that like to play. Professional athletes train 6 days a week, two times a day, for several hours. My dogs train two to three time a week for 5 to 10 minutes... (Coach Webpage)

Indeed, agility handlers could equally criticize pet caretakers; for family pets, the relationship between humans and dogs may be an unconditional one, but it potentially conflicts with the philosophies that one needs to follow to build successful relationship in daily life as well as in dog sport. Approaching non-human nature from the viewpoint of and for the benefit of categorically separate humans (Johnston 2008) and spoiling the dog with the wrong type of love, that is by anthropomorphizing these pets (e.g. Greenebaum 2004), may result in the dog's unwillingness to fully engage in agility, as she has not fully learned to act with the human as a team. Some coaches express their preference to teach young dogs, because those are easier to direct into the right type of mood; dogs starting agility at an older age are more prone to unwanted behaviour leading to injuries, as they have not been grown into the sport. Yet to maintain their own reputations and agility sport's public image as a dog-friendly, playlike activity, they cannot overlook potential customers who want to enter the sports with their pets. Therefore, the criticism is not expressed publicly but new hobbyists are directed towards the correct way to love their dogs and only after that, the most effective ways to train for the sport of agility. 


\section{Four manifestations of love in dog agility}

Our netnographic analysis of the Facebook statuses, blog texts and coaches' web pages identified four overlapping relationships manifesting loving relations. These are (1) handler's love for dog, (2) dog's love for handler, (3) handler's love of agility and (4) dog's love of agility. For analytical purposes, we will present these relationships as four ideal types of love. One should note, however, that the representations of love leak into and overlap these analytical categories, as will be elaborated in the closing discussion.

\section{Handler's love for dog}

Previous research on pet-related Internet groups (Golbeck 2011) has demonstrated that photo posting is a central activity, especially among pet dog caretakers. In the world of pets, it is important to portray the dog as a loving and loved family member. When the dogs are written about, they are typically presented as objects of admiration and sources of unconditional love. If the coaches post photos of dogs 'doing nothing', they contextualize these photos as having to do with training. Common examples are photos of a dog sleeping on a couch, which are then explained as 'my tired but happy dog after a great training session.'

In coaches' image-building, they pose with their dogs, often with both team members looking at the camera or each other and the human having his/her hand over the dog's neck. This constellation confirms the image of the handler and her dog as an equal, loving team. A constant feature of commenting these images is the abundant use of heart symbols for example in Facebook. This is because symbols overcome language barriers and are quickly interpreted. As a part of the agility coaching, 'love' is included in the descriptions of many daily professional actions: 
Nothing is cooler than run without pain and especially with [Fox], she is the most fun to run with, there is no words to describe how much I love her $<3$. (Coach Facebook update)

For pet owners, competitive persons may look as though they have dogs only to achieve success. Therefore, it is important to acquire and maintain a reputation as a person who is interested in the welfare of the dogs. For example, one of the training enterprises offers agility training methodology based on 'dogs' natural behaviour' and advertises that its ideology is 'dog-centred and suitable for all dogs'. Even if agility is a profession for these people and serious leisure for their clients, the 'dog's best' is never forgotten.

There are also cases where the love for dogs has become the core of the brand of the coach. Coach's love for dogs can be narrated from an autobiographic perspective accompanied by childhood photos showing how it all starting with the beloved family pet. Originally, love was probably not planned to characterize the agility coaching ideology, but in competing for customers in a steadily growing industry of agility coaching, some instructors make explicit use of their adorable attitude towards dogs. As one coach blogs about gratitude:

Now recall the first day you made the decision to get "that" puppy [...]. What was it about that particular one that made you take him home? [...] Next visualize that dog the last time you saw him sleeping in his favourite place around the house, where is he? [...] Think about how much you love that dog and how grateful you are to have him in your life. Now put this question out there for your "higher power" or just throw it on out there into the universe. "How can I help this dog to live with more joy and be more connected to me?" (Coach Webpage) 
Stories like this are not straightforwardly about agility, but they build up a greater narrative of the teamwork. The coach may not be the most athletic or competitive handler, but her agility performances are defined by a fun, loving attitude towards her dogs — and this is why she has become successful and gained a good reputation. In another case, a coach has created a commercially successful brand by always having fun with her dogs, always having them around with their playfulness, joy and speed, and having the ability to write and visualize this attitude for an international online audience. Even in this case, the love is embedded in the joint action: in training tricks (rather than in technical skills), in encouraging the love to run (instead of technical details of handling) and in intensive play together in a heavily crowded environment in order to build trust and manage any surprise or distraction the dog might experience in the competition ring. Being asked about the most important step in making a great agility dog, this is her answer:

Having a handler that knows how to listen, accept and adjust a training plan is the one most important thing that our agility dog needs in order to reach her full potential. (Coach Webpage)

It is the certain openness and honesty that makes us, when analysing this agility coaching enterprise, see love for dogs as a success which is less conditional upon competence than some other cases. There are no 'missing dogs,' that is, dogs that are introduced with high expectations but who disappear suddenly or appear less and less often in blog texts and results lists. Instead, difficulties with every individual dog are handled as a challenge, and the weaknesses of a single dog are recalled every now and then. 


\section{Dog's love for handler}

Researchers have provided compelling evidence that animals experience such emotions as love and grief (e.g. Bekoff 2000). In our material, love for the handler is often visualized and utilized when advertising the handler's coaching services online. Love is portrayed as and in an active relationship between the handler and the dog, thus deviating from the model of unconditional love often found in the world of pets. Descriptions of the dog's love for the handler are found especially when introducing coaches' dogs to the readers.

While [Fido] enjoys the sport, I think she mostly does it because she knows it makes me happy (and of course because I used alot of good dog training to grow her drive for the sport). But at the end of the day, she just wants to do what I do, and is not at all pleased with me if she is left behind when I go out to teach or train. (Coach Webpage)

The anthropomorphic unconditional love is formed into a companionship where the human provides the dog with activities through which both can show their love to each other. The handler is presented as providing the possibility for engaging and doing something meaningful together. Dogs love the activity their owners offer them, otherwise they would not voluntarily perform the tasks as precisely as they do (Lund 2014). Compared to that of the culture of dog caretakers, the line of thought of active competitors suggests that 'the dog does not love me more if I buy her a new toy — she loves me because she knows we are going to play together with the toy'. The pictures of the dog and handler together in intensive play after a winning course or on a relaxing walk in the forest after a long competition day enhance the image of the dog's love for the handler. It is important to show the enjoyment the dog receives from the training, because otherwise, the relationship between the handler and the dog may be interpreted 
as incomplete, that is, as morally unjust. Only a morally superior handler provides her dog with these pleasures.

\section{Handler's love of agility}

Many competitive agility handlers orient within agility in terms of serious leisure and sports. Among the successful agility handlers, many have previously been actively involved in some other sport such as football. For this reason, top-level agility has developed drastically as courses demand of the handler the bodily awareness, quick reactions, stamina and mental capacities to guide the dog from the start to the finish in the shortest possible time. Some coaches use extensive time and energy to explore the bodily aspects of the sport, creating new ways of thinking about and performing the teamwork. The teamwork in agility might then be a good example of activating 'the unlearned human potential for learning' also in other sports (Maguire 2011, 904).

These involvements emerge from the handler's love of agility. In this learning process, dogs are presented as important sources of mutual learning. Even the runs ending in disqualification are presented in social media as part of a continuous learning process. Small mistakes may ruin an otherwise perfect run or take away the victory, but learning from failings and distributing the learned knowledge through training session are noted by the coaches as the main reasons for engaging in dog sports.

Instead of asking why your dog does this [mistake] repeatedly, ask yourself what it is in your handling that causes the problem. (Coach Webpage)

Nice running contacts [a special technique to perform an obstacle on the course] in today's trials. The work is finally starting to pay off. (Coach Facebook update) 
I'm a perfectionist when it comes to training dogs. Therefore I'm always teaching people to get to the top... as long as they don't beat me. (Coach Webpage)

This seriousness and sportiness is also shown in photos representing the coaches as active competitors. Coaches do not only pose side by side with their dogs. Showing the coach's serious engagement in and passion for the sport is achieved, for example, with images of fast dog-handler teams running the course, the handler walking determinedly in the ring wearing a number vest or celebrating victories together with friends or business companions wearing national team clothes.

The combination of the love of agility and love for dogs and especially love for a certain dog can be seen in the names given to different enterprise-related things. For example, the training facility is named after an important dog, or the name of the enterprise is an adaptation of a dog name. While the current high-performance dog is most visible in postings about competitive events, it is often the first successful competition dog is narrated into the story of coach's entrance to the sport. For some coaches, their own professionalism and branding gets the most attention, and (several, changing) competition dogs are not mentioned so often. In these cases, it is the name of the handler that gives clients the guarantee of quality. A firm named after these selfbranded persons is, first of all, professional and sterling; only secondly, when looking at the pictures and reading the presentation texts, does it include co-operating with dogs. Again, we are not claiming anything about these coaches' actual love for their dogs; it is just to what degree 'the love' is utilized in creating successful business career in agility.

\section{Dog's love of agility}

Agility is a human invention in the sense that it is not based on any species-specific behaviour that dogs would naturally engage in (such as greyhound racing or hunting). 
The dog's love of agility is facilitated by first teaching the dog to love the rewards received from the handler. These stepwise phases on the way to the top are shown in the pictures of intensive, focused tugging games to illustrate the methods of rewarding the dog for the correct action. After the dog has learnt to love agility, videos showing eager, playful dogs performing in trials and training sessions are commonly used as evidence to show how the dogs enjoy the sport as much as the handler does: 'All of my dogs have loved agility. They would just go crazy to play.'

Therefore, what a loving handler does is to respect and respond to the dog's love of running and playing (Lund 2014, 104). Sometimes the dog's emotions are represented in an anthropomorphized manner in social media, as if the dog was writing: 'I had such a great time in agility trainings again. I think I did it amazingly!' The message may be reinforced by a picture of a panting dog. As Haraway (2003) points out, dogs not only have bodies capable of suffering (Atkinson and Young 2005) and, by this, showing us what we should not do, but they also have bodies 'capable of work and play, satisfaction and pleasure' (Lund 2014, 104). The dog is represented as loving her sporty and active lifestyle and — as a counterpart — enjoying the cosy family life outside the training and competitions.

Although the fun comes out of the teamwork with the handler, the dog's love of agility is not the same as the dog's love for the handler. This can be illustrated by the handlers' sharing videos of how the dogs manage to run winning courses even with handlers other than their own:

First time ever I did agility with my student's border collie [Fido] $\odot$ If dog is well trained with [our] system, it is no matter who is the handler. Clean run and 5th place, thanks [Lisa] and get well soon! (Coach Facebook Update) 
Handlers switching dogs in competitions resembles the situation of professional jockeys in horse racing, who may 'have little or no knowledge of the animal which they are to pilot' (Vamplew 2015, 7). For the critics, the same situation can be interpreted to demonstrate that the companion aspects of the dog sport are eroding, and dogs are simply becoming interchangeable objects and widgets in handlers' investment in serious sports. This is a good remainder of the contrasting ways in which audiences may interpret social media content: while the reason behind switching the handler may have been a very practical one (first handler being unable to attend), the narrative of the event may be utilized to market the training philosophy of the coach.

\section{Discussion: Love as the skill of dogmanship}

Building the ideal companionship as well as teaching and learning together with the dog to love the sport are the first steps towards a winning course. As one of the 'Ten Agility Commandments' published by one of the coaching enterprises states, 'Be the best possible teammate for your dog.' Morrison, Johnston and Longhurst $(2013,516)$ ask researchers to consider more deeply what love does. The challenge for researchers is to 'seek to make nonhumans visible in order to ensure that their material (and in some cases, emotional) needs are not unthinkingly ignored or automatically placed below our own' (Johnston 2008, 646). In dog agility, the human actor cannot succeed without including the non-human teammate within the same performative bubble, which is sustained not only by individual skills and handling techniques but also by emotional competence. Again, paraphrasing one of the Ten Agility Commandments, 'Your skill is on the same level as your emotions.'

In some subcultures of dog hobbies, dog sports as a serious leisure is seen to express attitudes which are condemned as inappropriate by both lay hobbyists and professionals. While in some dog sport, one can find people who openly advertise the 
use of learning tools and techniques that may cause pain to the dogs, in agility, none of the coaches admit using negative reinforcement. On the contrary, some top coaches underline that they would like competence-oriented people to better remember the pet ownership part of their doggy life and learn about it. They highlight that they share their life and home with their dogs, whom they love and respect equally. It is through this mutual understanding and respect that many of the coaches have become the skilful competitors and coaches who they are today.

However, controlling the ways in which the students handle their dogs and following their lifestyle is difficult, both for interactional reasons — it is a hard moral choice to say to customers that they do not seem to be giving their dog enough love and affection in the form of respect and presence - and because of more and more common online coaching in which all the coach gets to see and comment on are videos of training sessions and competitions. In these cases, the coaching is mainly a matter of learning handling cues, making a handling plan for a course and mentally managing one's own competition behaviour. However, when contextualized with love as a teambuilding tool also online lessons can help in developing the skill of real dogmanship, the relationship between the owner and the dog. A series with several lessons allows more space for in-depth instruction in how to develop a smooth everyday life with a pet dog, which an agility dog should also be. To get as much as possible out of the love for agility, there also must be the human's love for his/her dog and the dog partner's love for agility, both of which (but especially the latter) can be learned under the right kind of guidance, which hopefully remains an integral part of professional agility coaching.

We started with the proposition that the world of competitive agility is constructed between ordinary pet caretakers and the world of serious sports. This is because in order to win, a team is needed, a dog and her handler having a particular 
connection characterized by four different types of love: the handler's love for the dog and for agility as well as the dog's love for the handler and for agility. The potential non-consumerability of unconditional love associated with pet culture and serious sport oscillates through the possession of practical, everyday-level skills, that is, of dogmanship. Rather than being a measurable thing, dogmanship is about living a relationship and a continuous process, the results of which come above all in the form of happy dog, and, sometimes, successful agility performance.

Working within affective economies — as agility coaches do — the impression of skills is given extensively in social media. Social media enables community building and the displaying of emotions. At the same time, for some, it also becomes a space taken over by commercialization and profit-making. Framing agility as a competitive sport comes with the risk of losing the existing strong connection to the world of companion species with its intrinsic moral codes, but our conclusion however is by supposing the presentations of love from coaches, social media act in preventing plain competitiveness. To study more deeply the reciprocal learning and 'love' of humans and non-humans in a Harawayan sense, more observational research is needed against which to read the textual and visual messages studied here.

\section{References}

Ahmed, Sara. 2004. “Affective Economies”. Social Text 22 (2): 117-139.

Apelmo, Elisabet. 2012. "Falling in love with a wheelchair: enabling/disabling technologies." Sport in Society: Cultures, Commerce, Media, Politics 15 (3): 399-408.

Atkinson, Michael, and Kevin Young. 2005. "Reservoir Dogs: Greyhound Racing, Mimesis and Sports-Related Violence." International Review for the Sociology of Sport 40 (4): 335-356.

Baldwin, Cheryl K., and Patricia A. Norris. 1999. "Exploring the dimensions of serious leisure: 'love me-love my dog!'.’ Journal of Leisure Research 31 (1): 1-17. 
Beck, Alan M., and Aaron Katcher. 1996. Between pets and people: the importance of animal companionship. West Lafayette: Purdue University Press.

Bekoff, Marc. 2000. “Animal Emotions: Exploring Passionate Natures.” BioScience 50 (10): 861-870.

Caudwell, Jayne. 2015. “'I Just Love Watching Football'.” In Sport and the Social Significance of Pleasure, edited by Richard Pringle, Robert E. Rinehart, and Jayne Caudwell, 133-150. New York: Routledge.

Connor, James. 2009. "The athlete as widget: how exploitation explains elite sport." Sport in Society: Cultures, Commerce, Media, Politics 12 (10): 1369-1377.

Cuskelly, Graham, Maureen Harrington, and Robert A. Stebbins. 2002. "Changing levels of organizational commitment amongst sport volunteers: A serious leisure approach.” Leisure/Loisir 27 (3-4): 191-212.

Eitzen, D. Stanley. 1989. “The sociology of amateur sport: An overview.” International Review for the Sociology of Sport 24 (2): 95-105.

Gilbert, Michelle, and James Gillett. 2012. "Equine athletes and interspecies sport." International Review for the Sociology of Sport 47 (5): 632-643.

Gillespie, Dair L., Ann Leffler, and Elinor Lerner. 2002. "If it weren't for my hobby, I'd have a life: dog sports, serious leisure, and boundary negotiations." Leisure Studies 21 (3-4): 285-304.

Gillett, James, and Michelle Gilbert, eds. 2014. Sport, Animals, and Society. New York: Routledge.

Golbeck, Jennifer. 2011. "The more people I meet, the more I like my dog: a study of pet-oriented social networks on the Web." First Monday 16 (2). url:http://firstmonday.org/ojs/index.php/fm/article/view/2859/2765.

Greenebaum, Jessica. 2004. 'It's a dog's life: elevating status from pet to 'fur baby' at Yappy Hour." Society \& Animals 12 (2): 117-135.

Haraway, Donna. 2003. The companion species manifesto: dogs, people, and significant otherness. Chicago: Prickly Paradigm Press.

Haraway, Donna J. 2008. When Species Meet. Minneapolis, London: University of Minnesota Press.

Hardman, Alun R., and Carwyn Jones. 2011. "Sports Coaching and Virtue Ethics". In The Ethics of Sports Coaching, edited by Alun R. Hardman, and Carwyn Jones, 71-84. Abingdon: Routledge. 
Hardt, Michael and Antonio Negri. 2004. Multitude: War and Democracy in the Age of Empire. New York: Penguin.

Harvey, Andy, and Agnieszka Piotrowska. 2013. "Intolerance and joy, violence and love among male football fans: towards a psychosocial explanation of 'excessive' behaviours." Sport in Society: Cultures, Commerce, Media, Politics 16 (10): 1404-1413.

Illouz, Eva. 2007. Cold Intimacies: The Making of Emotional Capitalism. Cambridge: Polity Press.

Johnston, Catherine. 2008. "Beyond the clearing: Towards a dwelt animal geography." Progress in Human Geography 32 (5): 633-649.

Keller, Heidi E., and Sandra Lee. 2003. "Ethical issues surrounding human participants research using the Internet." Ethics and Behavior 13 (3): 211-219.

Kozinets, Robert. 2010. Netnography: Doing Ethnographic Research Online. London: Sage.

Lebel, Katie. 2014. "Professional Athlete Self-Presentation on Twitter.” PhD diss., University of Western Ontario. Electronic Thesis and Dissertation Repository. Paper 1303. http://ir.lib.uwo.ca/etd/1303.

Lund, Giuliana. 2014. "Taking Teamwork Seriously: The Sport of Dog Agility as an Ethical Model of Cross-Species Companionship.” In Sport, Animals, and Society, edited by James Gillett, and Michelle Gilbert, 101-123. New York: Routledge.

Maguire, Joseph A. 2011. "Human sciences, sports sciences and the need to study people 'in the round'." Sport in Society. Cultures, Commerce, Media, Politics 14 (7-8): 898-912.

Morrison, Carey-Ann, Lynda Johnston, and Robyn Longhurst. 2013. “Critical geographies of love as spatial, relational and political." Progress in Human Geography 37 (4): 505-521.

Morrow, Oona, Roberta Hawkins, and Leslie Kern. 2015. "Feminist research in online spaces." Gender, Place \& Culture: A Journal of Feminist Geography 22 (4): 526-543.

Nast, Heidi J. 2006a. “Critical pet studies?” Antipode 38 (5): 894-906.

Nast, Heidi J. 2006b. "Loving ... whatever: alienation, neoliberalism and pet love in the twenty-first century." ACME: An International E-Journal of Critical Geographies 5 (2): 300-327. 
Pastore, Camilla, Federica Pirrone, Francesca Balzarotti, Massimo Faustini, Ludovoca Pierantoni, and Mariangela Albertini. 2011. "Evaluation of physiological and behavioral stress-dependent parameters in agility dogs." Journal of Veterinary Behavior: Clinical Applications and Research 6 (3): 188-194.

Pegoraro, Ann. 2010. “Look Who’s Talking_Athletes on Twitter: A Case Study.” International Journal of Sport Communication 3 (4), 501-514.

Postmes, Tom, Russell Spears, and Martin Lea. 1998. "Breaching or building social boundaries? SIDE-effects of computer-mediated communication." Communication Research 25 (6): 689-715.

Raisborough, Jayne. 1999. "Research note: the concept of serious leisure and women's experiences of the Sea Cadet Corps." Leisure Studies 18 (1): 67-71.

Rinehart, Robert E. 2000. "Emerging Arriving Sport: Alternatives to Formal Sports.” In Handbook of Sport Studies, edited by Jay J. Coakley, and Eric Dunning, 504520. London: Sage.

Salasuo, Mikko, Mikko Piispa, and Helena Huhta. 2015. Huippu-urheilijan elämänkulku. Tutkimus urheilijoista 2000-luvun Suomessa. Helsinki: Nuorisotutkimusseura.

Schinke, Robert J., Gordon A. Bloom, and John H. Salmela. 1995. “The Career Stages of Elite Canadian Basketball Coaches." Avante 1 (1): 48-62.

Schuurman, Nora. 2014. "Blogging situated emotions in human-horse relationships." Emotion, Space and Society 13 (4): 1-8.

Stebbins, Robert A. 1992. Amateurs, Professionals, and Serious Leisure. Montreal: McGill-Queen's University Press.

Stebbins, Robert A. 2006. Serious Leisure: A Perspective of Our Time. Calgary: Transaction.

Stebbins, Robert A. 2014. Careers in Serious Leisure: From Dabbler to Devotee in Search of Fulfilment. New York: Palgrave Macmillan.

Stokvis, Ruud. 2000. "Globalization, commercialization and individualization: Conflicts and changes in elite athletics." Culture, Sport, Society 3 (1), 22-34.

Taylor, Bill, and Dean Garratt. 2010. "The Professionalisation of Sports Coaching: Relations of Power, Resistance and Compliance.” Sport, Education and Society 15 (1): 121-139.

Vallerand, Robert J., Céline Blanchard, Geneviève A. Mageau, Richard Koestner, Catharine Ratelle, Maude Léonard, Marylène Gagné, and Josée Marsolais. 2003. 
"Les passions de l'âme: On obsessive and harmonious passion." Journal of Personality and Social Psychology 85 (4): 756-767.

Vallerand, Robert J., Geneviève A. Mageau, Andrew J. Elliot, Alexandre Dumais, Marc-André Demers, and François Rousseau. 2008. "Passion and performance attainment in sport." Psychology of Sport and Exercise 9 (3): 373-392.

Vamplew, Wray. 2015. "Still crazy after all those years: continuity in a changing labour market for professional jockeys." Sport in Society. Cultures, Commerce, Media, Politics doi:10.1080/17430437.2015.1059015.

Vänskä, Annamari. (2014). "New kids on the mall: Babyfied dogs as fashionable coconsumers." Young Consumers 15 (3): 263-272. 